\title{
CDH13 promoter methylation regulates cisplatin resistance of non-small cell lung cancer cells
}

\author{
YAN WANG $^{1}$, LEI ZHANG ${ }^{2}$, JIASHENG YANG $^{1}$, BIN LI $^{1}$ and JUN WANG ${ }^{1}$ \\ ${ }^{1}$ Guangdong Second Provincial General Hospital, Guangzhou, Guangdong 510317; \\ ${ }^{2}$ The Second Affiliated Hospital of Guangzhou Medical University, Guangzhou, Guangdong 510260, P.R. China
}

Received November 28, 2017; Accepted July 24, 2018

DOI: $10.3892 / 01.2018 .9325$

\begin{abstract}
Reversing cisplatin resistance of lung cancer cell line A549/DDP through recovering cadherin 13 (CDH13) expression by demethylation was investigated in the current study. RT-PCR was used to measure CDH13 expression in lung cancer A549 and A549/DDP cells with or without 5-Aza-CdR intervention. Methylation-specific PCR was used to detect CDH13 methylation. MTT assay and flow cytometry were used to measure the effects of cisplatin on inhibiting cell proliferation, apoptosis, and the reversal of cisplatin resistance. The $\mathrm{IC}_{50}$ value of cisplatin for A549 and A549/DDP cells was $3.278 \pm 0.532$ and $28.341 \pm 1.435 \mu \mathrm{mol} / \mathrm{l}$, respectively $(\mathrm{P}<0.05)$. The cisplatin-resistance index of A549/DDP cells was up to 8.65 . After $2.5,10$, or $40 \mu \mathrm{mol} / 1$-Aza-CdR treatment, the apoptotic rates of A549/DDP cells were 9.4 $\pm 0.86,18.1 \pm 1.42$ and $42 \pm 2.01 \%$, respectively, which were significantly different to those of the control group $(\mathrm{P}<0.05)$. Methylation-specific PCR detected both methylation (M) and unmethylation (U) bands at CDH13 promoter region before 5-Aza-CdR intervention while it only detected an unmethylation band after the treatment with a higher concentration of 5-Aza-CdR, which indicates the transformation to unmethylation state. When $10 \mu \mathrm{mol} / 15$-Aza-CdR was added, the $\mathrm{IC}_{50}$ of cisplatin to A549/DDP cells was $8.472 \pm 0.415 \mu \mathrm{mol} / 1$, and cisplatin resistance was reversed by 3.35 -fold. CDH13 methylation is related to the cisplatin resistance of A549/DDP cells. 5-Aza-CdR can inhibit CDH13 methylation and recover CDH13 expression. With the increase in 5-Aza-CdR concentration, the unmethylation state of CDH13 is enhanced, which can strengthen the
\end{abstract}

Correspondence to: Dr Yan Wang, Guangdong Second Provincial General Hospital, 466 Xingang Middle Road, Haizhu, Guangzhou, Guangdong 510317, P.R. China

E-mail: junwanghxk@163.com

Dr Lei Zhang, The Second Affiliated Hospital of Guangzhou Medical University, 250 Changgang East Road, Haizhu, Guangzhou, Guangdong 510260, P.R. China

E-mail: 3430350172@163.com

Key words: $\mathrm{CDH} 13$, methylation, non-small cell lung cancer, cisplatin function of cisplatin inhibiting proliferation and apoptosis in A549/DDP cells.

\section{Introduction}

Recently, several studies have shown that cadherin 13 (CDH13; T-cadherin, H-cadherin) functioned as an anti-oncogene and that its polymorphisms were associated with the development of different cancers (1-3).

CDH13 is a close phylogenetic relative of classical cadherins and shares with them the typical organization and overall sequence similarity of the extracellular domain (4). CDH13 is encoded by a single gene in each vertebrate genome, and is thought to have appeared recently in evolution as a result of duplication of a gene of a classical cadherin (4). Yet, the EC1 subdomain of CDH13 shows replacements of several amino acid residues crucial for homophilic interactions, in particular the Trp2Ile replacement. Therefore, it was suggested that CDH13 may be unable to efficiently form homodimers, which was supported by NMR studies (5). However, recent findings have identified a novel mechanism of homophilic adhesion of CDH13 (and possibly other nonclassical cadherins) via an alternative interface near the EC1-EC2 calcium-binding sites (6). Another unique feature of CDH13 is that it is devoid of a transmembrane domain and is anchored to the exterior surface of the plasma membrane via a glycosyl-phosphatidylinositol (GPI) anchor. Similar to all cadherins, CDH13 is glycosylated on several sites $(7,8)$. Structural and functional aspects of CDH13 have been covered in considerable detail in recent reviews $(9,10)$. The highest $\mathrm{CDH} 13$ expression has been reported in the nervous and cardiovascular system (in endothelial and smooth muscle cells). In this respect, it resembles type II cadherins, which are primarily expressed in the nervous system and vasculature (6), although CDH13 is closer to type I classical cadherins in terms of sequence similarity (4).

Classical cadherins are often located at and contribute to the formation of intercellular junctions. Loss of intercellular adhesion facilitates cell motility and growth. By contrast, CDH13 is not strongly associated with the areas of cell-cell contacts in confluent cell cultures, and shows globular punctate distribution (9). In migrating cells, it is located primarily at the leading edge (9). Recently, its nuclear and centrosomal location has been reported in endothelial cells (11). In HEK 293A cells, CDH13 was detected in the centrosomes but not in 
the nucleus (11). Nuclear localization of cleaved intracellular domains of some other members of the cadherin superfamily, such as protocadherins a (12), c (13) and Fat1 (14,15), as well as classical E-cadherin (16), N-cadherin (17) has been reported. Cleaved intracellular domains may act as transcription factors or modulate gene expression (18). However, CDH13 has no corresponding intracellular domain and presents in the nucleus as a full-length molecule (11); therefore, functional parallels with other cadherins may not be relevant in this case.

The CDH13 gene is a new member of the cadherin superfamily, which was isolated recently and has been mapped to $16 q 24$ (19). Cadherins are transmembrane glycoproteins expressed on the epithelial cell surface that mediate intercellular $\mathrm{Ca}^{2+}$-dependent adhesion, which is important for maintaining normal tissue structure. Abnormalities in the CDH13 gene have been identified in human malignancies (20,21). Moreover, an association between the abnormal expression of CDH13 and its promoter methylation in lung cancer has been demonstrated (22-24). Recent studies have reported that $\mathrm{CDH} 13$ functioned as an anti-oncogene in lung (1), breast (25), ovarian (3), bladder (26), esophageal (27) and gastric cancer (28).

CDH13 promoter methylation plays a key role in cancer development by promoting the inactivation of tumor suppressor genes, activation of oncogenes, and increase in chromosomal instability (29). This study investigated the mechanism between CDH13 promoter methylation and the drug resistance of lung cancer cells during chemotherapy and aimed to clarify whether $\mathrm{CDH} 13$ can serve as a molecular marker for predicting the efficacy of cisplatin treatment during adjuvant chemotherapy.

\section{Materials and methods}

Materials. A549, a human lung adenocarcinoma cell line (obtained from the American Type Culture Collection and preserved by the Respiratory Department of the Second People's Hospital of Guangdong); A549/DDP, a drug-resistant cell line of lung adenocarcinoma (purchased from the Cell Resource Center of Shanghai Institutes for Biological Sciences, Chinese Academy of Sciences, Shanghai, China); cisplatin (Qilu Pharmaceutical Co., Ltd., Jinan, China); 5-Aza-CdR (Sigma-Aldrich; Merck KGaA, Darmstadt, Germany); the Methylcode $^{\mathrm{TM}}$ Bisulfite Conversion kit and the total RNA isolation reagent TRIzol (Invitrogen; Thermo Fisher Scientific, Inc., Waltham, MA, USA); the reverse transcription kit (Qiagen $\mathrm{GmbH}$, Hilden, Germany). Cells were divided into 7 groups to measure CDH13 mRNA expression level. Group 1 was A549 cells with no 5-Aza-CdR treatment, and groups 2-7 were the A549/DDP cells with different concentration (0, 0.5, 1, 5, 10, and $20 \mu \mathrm{mol} / \mathrm{l}$ ) of 5 -Aza-CdR treated in $48 \mathrm{~h}$. The study was approved by the Ethics Committee of Guangdong Second Provincial General Hospital (Guangzhou, China).

\section{Methods}

Measurement of CDH13 mRNA expression level by transcription-polymerase chain reaction (RT-PCR). According to the principles of PCR primer design, $\mathrm{CDH} 13$ and GAPDH primers were designed. GAPDH served as the positive control for RT-PCR.PCR primers were produced by the Beijing Genomics
Institute (Beijing, China). CDH13 primers were F5'-AGTGTT CCATATCAATCAATCAGCCAG-3' and R5'-CGAGACCTC ATAGCGTAGCTT-3'. GAPDH primers were F5'-GAAAGC CTGCCGGTGACTAA-3' and R5'-GCCCAATACGACCAA ATCAGAG-3'.

The PCR solution (25 $\mu \mathrm{l})$ contained $12.5 \mu 12 \mathrm{X}$ PCR Master Mix, $0.5 \mu \mathrm{l}$ of each primer $(25 \mu \mathrm{mol} / \mathrm{l}), 1 \mu \mathrm{l}$ DNA template, and DEPC water. The PCR reaction conditions for CDH13 and GAPDH: $5 \mu \mathrm{l}$ cDNA, $10 \mu 1 \mathrm{SYBR}^{\circledR}$ Premix Ex Taq ${ }^{\mathrm{TM}}$ (Tli RNaseH Plus) (2X Conc.) (Takara Bio, Inc., Otsu, Japan),

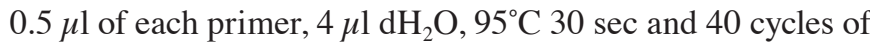
$95^{\circ} \mathrm{C} 3 \mathrm{sec}$ and $60^{\circ} \mathrm{C} 34 \mathrm{sec}$. Each of $5 \mu \mathrm{l} \mathrm{PCR}$ products was separated in $0.15 \%$ agarose gel by electrophoresis for $20 \mathrm{~min}$.

Detection of CDH13 methylation in cell lines. The EZDNA methylation kit (Zymo Research, Orange, CA, USA) was used to perform DNA methylation. A total of $900 \mu 1$ sterile ultrapure water, $50 \mu \mathrm{l} \mathrm{M}$-dissolving buffer, and $300 \mu \mathrm{l} \mathrm{M}$-dilution buffer were added into a CT conversion reagent tube. The solution was mixed by agitation. In each PCR tube, $20 \mu 1$ DNA was added into $130 \mu \mathrm{l} \mathrm{CT}$ conversion reagent. The PCR tubes were placed into the PCR instrument and kept at $98^{\circ} \mathrm{C}$ for $10 \mathrm{~min}$ and then $64^{\circ} \mathrm{C}$ for $2.5 \mathrm{~h}$. Then, $600 \mu \mathrm{l}$ M-binding buffer was added into the purification column which was inserted into a liquid collection tube. The sample was added into the purification column, and the tube was centrifuged at $10,000 \mathrm{x} g$ for $30 \mathrm{sec}$ at $4^{\circ} \mathrm{C}$. The liquid in collection tube was discarded and $100 \mu \mathrm{l} \mathrm{M}$-wash buffer was added into the purification column. The tube was centrifuged at $10,000 \mathrm{x}$ g for $30 \mathrm{sec}$ at $4^{\circ} \mathrm{C}$ and the liquid in collection tube was discarded. A total of $200 \mu 1$ M-desulphonation buffer was added into the purification column and left at room temperature for $20 \mathrm{~min}$. The tube was centrifuged at $10,000 \times \mathrm{g}$ for $30 \mathrm{sec}$ at $4^{\circ} \mathrm{C}$. A total of $200 \mu \mathrm{l}$ $\mathrm{M}$-wash buffer was added and the tube was centrifuged at $10,000 \mathrm{xg}$ for $30 \mathrm{sec}$ at $4^{\circ} \mathrm{C}$, and the step was repeat once. The liquid in collection tube was discarded and $20 \mu \mathrm{l}$ M-elution buffer was added to elute the DNA. The tube was centrifuged at $10,000 \mathrm{x}$ for $30 \mathrm{sec}$ at $4^{\circ} \mathrm{C}$, and the eluted solution was used for PCR amplification.

Detection of DNA methylation using methylation-specific $P C R(M S P)$. The primer sequences for detecting CDH13 methylation (the length of amplified fragments was $243 \mathrm{bp}$ ) were: F, 5'-TCGCGGGGTTCGTTTTTCGC-3', R, 5'-GACGTTTTC ATTCATACACGCG-3'; and primer sequences for detecting CDH13 unmethylation (the length of amplified fragments was 242 bp) were: F, 5'-TTGTGGGGTTTGTTTTTTGT-3', R, 5'-A ACTTTTCATTCATACACACA-3'.

PCR amplification: in $20 \mu \mathrm{l}$ PCR solution, the blood genomic DNA of healthy subjects was treated by the methylase SssI and served as the positive control, and that not treated by $S s s$ I served as the negative control. Sterile double-distilled water served as the blank control. The amplification conditions were 12 cycles of $94^{\circ} \mathrm{C} 30 \mathrm{sec}, 64^{\circ} \mathrm{C} 30 \mathrm{sec}$, and $72^{\circ} \mathrm{C}$ $40 \mathrm{sec}$. PCR product $(5 \mu \mathrm{l})$ of methylation or unmethylation DNA template was mixed with $1 \mu 1$ loading buffer and then subjected to gel electrophoresis. The gel was stained by using a nucleic acid silver staining kit (Beijing Dingguo Changsheng Biotechnology Co., Ltd., Beijing, China) according to the manufacturer's protocol. 
Methylation of blood genomic DNA from healthy subjects: the reaction system $(50 \mu \mathrm{l})$ contained $5 \mu \mathrm{l} 10 \mathrm{X}$ NBE buffer, $0.25 \mu 1$ SAM (32 mM), 2 U SssI methylase, $2 \mu 1$ DNA, and $40.75 \mu \mathrm{l}$ sterile double-distilled water. It was placed in a $37^{\circ} \mathrm{C}$ water bath for $3 \mathrm{~h}$ and then $65^{\circ} \mathrm{C}$ water bath for $10 \mathrm{~min}$. Then, $6 \mu \mathrm{l}$ PCR product was mixed with $2 \mu 1$ loading buffer and loaded into a $2 \%$ agarose gel containing a nucleic acid dye. Electrophoresis was performed at $120 \mathrm{~V}$ for $30 \mathrm{~min}$. The gel was observed under a gel imaging system (UVP).

Detecting the reversal of drug resistance in A549/DDP cells by MTT. Concentrations of $0,1.25,2.5,5,7.5$, and $10 \mu \mathrm{mol} / 1$ of cisplatin were used to treat A549 cells, and 0, 10, 20, 30, 40 and $50 \mu \mathrm{mol} / 1$ cisplatin was used to treat A549/DDP cells.

Following treatment with a non-toxic dose of 5-Aza-CdR (10 $\mu \mathrm{mol} / \mathrm{l})$ for $48 \mathrm{~h}$, A549/DDP cells were treated with cisplatin (the same concentrations as above) for $48 \mathrm{~h}$. For the control group, an equal volume of DMSO was added. Each group had 3 repeats. After 48 h, $20 \mu \mathrm{l}$ MTT $(5 \mathrm{mg} / \mathrm{ml})$ was added to each well. After $4 \mathrm{~h}$ of culture, the culture medium was centrifuged at $2,000 \mathrm{x}$ g for $10 \mathrm{~min}$ at $4^{\circ} \mathrm{C}$. The supernatant was discarded, and $150 \mu 1$ DMSO was added into each well. After MTT was completely dissolved, OD $490 \mathrm{~nm}$ was measured in a microplate reader and cell viability was calculated. Inhibition rate (\%) was calculated as: (A492 of control cells - A492 of intervened cells)/A492 of control cells x100\%. Reversal index of drug resistance $=\mathrm{IC}_{50}$ of the drug-resistant cells only treated with cisplatin/ $/ \mathrm{IC}_{50}$ of the drug-resistant cells treated with both cisplatin and 5-Aza-CdR. Drug resistance index $=\mathrm{IC}_{50}$ of drug-resistant cells/ $/ \mathrm{IC}_{50}$ of parental cells.

Morphological changes of cisplatin-treated apoptotic A549/DDP cells before and after 5-Aza-CdR intervention detected by Hoechst 33258. The cells in the logarithmic growth phase were inoculated into 6-well cell culture plates $\left(3 \times 10^{5} /\right.$ well). The cells were then divided into four groups: i) A549/DDP group; ii) A549/DDP + 5-Aza-CdR (10 $\mu \mathrm{mol} / \mathrm{l} ; 48 \mathrm{~h})$ group; iii) A549/DDP + DDP $(20 \mu \mathrm{mol} / \mathrm{l})$ group; iv) A549/DDP + 5-Aza-CdR (10 $\mu \mathrm{mol} / \mathrm{l} ; 48 \mathrm{~h})+$ DDP (20 $\mu \mathrm{mol} / \mathrm{l})$ group. The cells were cultured in $2 \mathrm{ml}$ medium/well at $37^{\circ} \mathrm{C}$ and $5 \% \mathrm{CO}_{2}$ for $48 \mathrm{~h}$. The culture medium was discarded, and $0.5 \mathrm{ml} 4 \%$ paraformaldehyde solution was added to fix the cells for $10 \mathrm{~min}$. The cells were washed twice with PBS for 3 min each time. The cells were treated with $1 \mathrm{ml}$ Hoechst 33258 staining solution $(10 \mu \mathrm{g} / \mathrm{ml})$ for $5 \mathrm{~min}$. The staining solution was discarded, and the cells were rinsed 3 times with PBS for 5 min each time. One drop of antifluorescence quenching liquid was added onto the coverslip which was then observed under a fluorescence microscope (IX70, Olympus Corporation, Tokyo, Japan).

Measurement of cisplatin-induced A549/DDP cell apoptosis before and after 5-Aza-CdR intervention by flow cytometry. Cells in the logarithmic growth phase were cultured at $37^{\circ} \mathrm{C}$ and $5 \% \mathrm{CO}_{2}$ for $48 \mathrm{~h}$, and $1 \mathrm{ml}$ cell suspension $\left(2.5-5 \times 10^{5} / \mathrm{ml}\right)$ was transferred into a $5 \mathrm{ml}$ centrifuge tube which was centrifuged at $1,000 \mathrm{x} \mathrm{g}$ at $4^{\circ} \mathrm{C}$ for $5 \mathrm{~min}$. The supernatant was discarded and the precipitate was rinsed twice with PBS. The precipitate was dissolved with $200 \mu \mathrm{l}$ binding buffer, and the solution was treated with $10 \mu \mathrm{l}$ FITC-labeled Annexin-V and $5 \mu 1$ PI in the dark for $15 \mathrm{~min}$. After adding $300 \mu \mathrm{l}$ binding buffer, the solution was measured by flow cytometry. At the same time, three control groups were conducted respectively as follows: i) unstained cells; ii) the cells stained only by AnnexinV-FITC; iii) the cells stained only by PI. The concentrations of cisplatin treatment for A549/DDP cells were 0, 2.5, 10 and $40 \mu \mathrm{mol} / 1$ respectively, for $48 \mathrm{~h}$. After $48 \mathrm{~h}$ of 5 -Aza-CdR $(10 \mu \mathrm{mol} / \mathrm{l})$ and A549/DDP, the concentration of cisplatin treatment for A549/DDP cells and the time were the same as above.

Statistical analysis. Data were analyzed using SPSS 16.0 software (SPSS, Inc., Chicago, IL, USA). The quantitative data following a normal distribution are presented by mean \pm standard deviation. Analysis of variance and post hoc test (Least Significant Difference) was used to compare more than two groups of data following a normal distribution. The t-test was used to compare the data between two groups. $\mathrm{P}<0.05$ was considered to indicate a statistically significant difference. $\mathrm{IC}_{50}$ was calculated using linear regression.

\section{Results}

CDH13 mRNA expression levels in A549 cells and A549/DDP cells. CDH13 mRNA expression levels in A549 cells and A549/DDP cells were measured by RT-PCR. The OD value of GAPDH served as the internal reference. The relative CDH13 mRNA expression level was represented by the ratio of $\mathrm{CDH} 13$ OD value to GAPDH OD value. The PCR products of A549 cells and A549/DDP cells showed a CDH13 band with the size of 243 bp (Table I; Fig. 1). The CDH13 mRNA expression level in A549 cells was significantly higher than that of A549/DDP concentration. CDH13 mRNA expression level was upregulated, indicating that at a certain range, the relative expression of CDH13 mRNA increased with the increase of 5-Aza-CdR concentration. The CDH13 mRNA expression level in A549/DDP cells with $10.0 \mu \mathrm{mol} / 1$ or $20.0 \mu \mathrm{mol} / 1$ 5-Aza-CdR treatment showed no significant difference ( $\mathrm{P}>0.05$ ), indicating that $10.0 \mu \mathrm{mol} / 1$ 5-Aza-CdR treatment can already induce a high expression level of CDH13 mRNA in A549/DDP cells.

CDH13 promoter methylation in $A 549$ and A549/DDP cells before 5-Aza-CdR intervention and that in A549/DDP cells after 5-Aza-CdR intervention. MSP was used to measure CDH13 methylation level in A549 and A549/DDP cells. The results showed that A549 cells only had an unmethylation band (U) of CDH13 (Figs. 2 and 3). Drug-resistant A549/DDP cells had both methylation (M) and unmethylation (U) bands of CDH13, which suggests the partial methylation of CDH13. When treated with a non-toxic dose of 5-Aza-CdR $(10 \mu \mathrm{mol} / \mathrm{l})$, A549/DDP cells showed an unmethylation band. The average OD values before and after 5-Aza-CdR treatment were calculated by the gel electrophoresis software QuantityOne and showed a statistically significant difference $(\mathrm{P}<0.05)$.

Results of reversal of drug resistance of A549/DDP before and after 5-Aza-CdR intervention detected by MTT. MTT results showed that the $\mathrm{IC}_{50}$ value of A549 cells with $48 \mathrm{~h}$ cisplatin treatment was $3.278 \pm 0.532 \mu \mathrm{mol} / 1$, while that of A549/DDP cells was 28.341 $\pm 1.435 \mu \mathrm{mol} / 1$ (8.65-fold) (Fig. 4). 
Table I. Relative CDH13 mRNA expression levels in A549 and A549/DDP cells treated with different concentrations of 5-Aza-CdR (mean \pm standard deviation).

\begin{tabular}{lc}
\hline No. & Relative CDH13 mRNA expression levels \\
\hline 1 & $0.8395 \pm 0.0045^{\mathrm{a}}$ \\
2 & $0.2797 \pm 0.0041^{\mathrm{b}}$ \\
3 & $0.3421 \pm 0.0037^{\mathrm{b}}$ \\
4 & $0.4735 \pm 0.0016^{\mathrm{b}}$ \\
5 & $0.6383 \pm 0.0051^{\mathrm{b}}$ \\
6 & $0.8381 \pm 0.0034^{\mathrm{b}}$ \\
7 & $0.8393 \pm 0.0056$ \\
\hline
\end{tabular}

${ }^{\mathrm{a}} \mathrm{P}<0.05$, comparison with the group $2 .{ }^{\mathrm{b}} \mathrm{P}<0.05$, six groups were compared pairwise. Group 1 was A549 cells with no 5-Aza-CdR treatment, groups 2-7 were the A549/DDP cells with different concentration $(0,0.5,1,5,10$, and $20 \mu \mathrm{mol} / 1)$ of 5 -Aza-CdR treated in 48 h. CDH13, cadherin 13 .

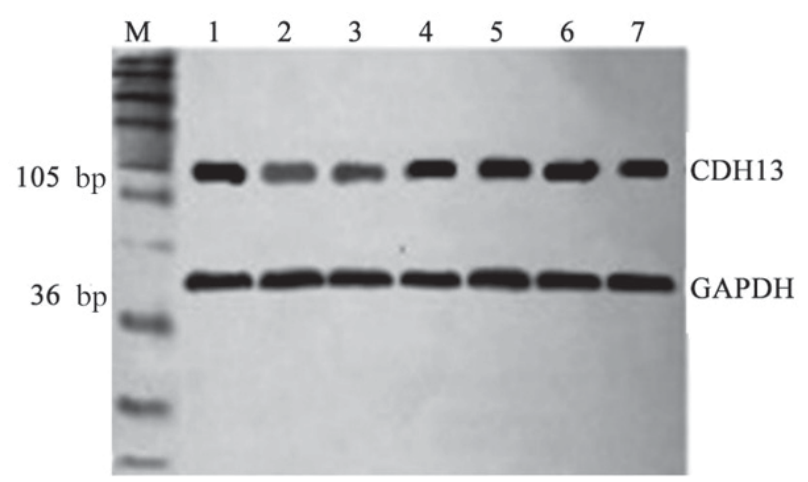

Figure 1. The RT-PCR results of A549 and A549/DDP cells. Lane 1 was the RT-PCR results of CDH13 mRNA in A549 cells; lanes 2-7 were the RT-PCR results of CDH13 mRNA in A549/DDP cells treated with 0, 0.5, 1, 5, 10, and $20 \mu \mathrm{mol} / 1$ 5-Aza-CdR, respectively. CDH13, cadherin 13.

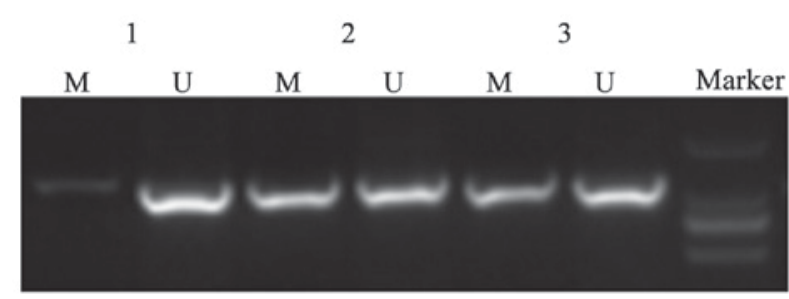

Figure 2. Electrophoresis results of MSP products. MSP, methylation-specific PCR.

It demonstrated that cisplatin could inhibit A549/DDP cell proliferation. However, A549/DDP cells showed a stronger cisplatin tolerance than that of A549 cells. After $48 \mathrm{~h}$ of $10 \mu \mathrm{mol} / 15$-Aza-CdR treatment, the $\mathrm{IC}_{50}$ value of A549/DDP cells was $8.472 \pm 0.415 \mu \mathrm{mol} / 1$, and the reversal index of cisplatin resistance was 3.35. These results indicated that $10 \mu \mathrm{mol} / 1$ 5-Aza-CdR treatment can increase the cisplatin sensitivity of A549/DDP cells. However, A549/DDP cells still showed a significantly lower cisplatin sensitivity than that of A549 cells $(\mathrm{P}<0.05)$.

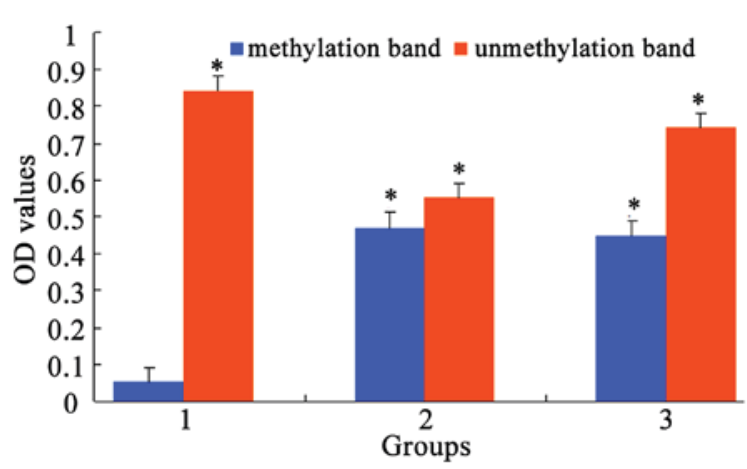

Figure 3. MSP method for detecting the average OD values of the methylation status of the $C D H 13$ gene. Group 1, A549/DDP cells treated with $40 \mu \mathrm{mol} / 1$ 5-Aza-CdR; group 2, A549/DDP cells treated with $20 \mu \mathrm{mol} / 1$ 5-Aza-CdR; group 3, A549/DDP cells. M, methylation band; U, unmethylation band. CDH13, cadherin 13; MSP, methylation-specific PCR. "P $<0.05$, compared with methylation band of Group 1.

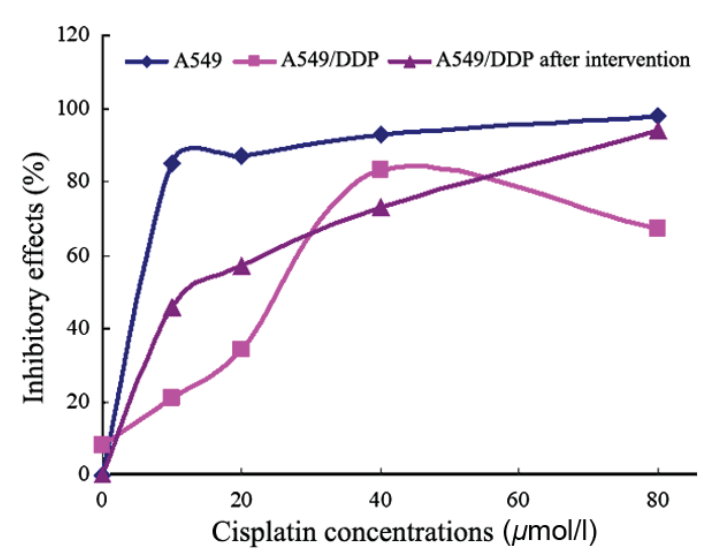

Figure 4. The inhibitory effects of different concentrations of cisplatin on A549 and A549/DDP cells,

Table II. Comparison of apoptotic ratios of cisplatin-treated A549/DDP cells before and after 5-Aza-CdR intervention.

\begin{tabular}{lllll}
\hline & \multicolumn{4}{c}{ Apoptotic ratios/\% (mean \pm standard deviation) } \\
\cline { 2 - 5 } & $0 \mu \mathrm{mol} / 1$ & $2.5 \mu \mathrm{mol} / 1$ & $10 \mu \mathrm{mol} / 1$ & $40 \mu \mathrm{mol} / 1$ \\
\hline $\begin{array}{l}\text { A549/DDP } \\
\text { cells after } \\
\text { 5-Aza-CdR } \\
\text { intervention }\end{array}$ & $0.80 \pm 0.10$ & $9.40 \pm 0.86$ & $18.10 \pm 1.42$ & $42.00 \pm 2.01$ \\
\hline
\end{tabular}

Morphological changes of cell apoptosis detected by Hoechst 33258. The results showed that in cell apoptosis, the uptake of Hoechst 33258 by cell membrane was increased (Fig. 5). Since the chromosomes were in a highly condensed state, their binding with Hoechst 33258 was strong, and the stained chromosomes showed a strong blue fluorescence. The chromosomes of normal cells only showed a weak fluorescence, and the dead cells were not stained. After $48 \mathrm{~h}$ of $10 \mu \mathrm{mol} / 1$ 5-Aza-CdR intervention, A549/DDP cells showed normal (round) morphologies and weak blue fluorescence, and there was few apoptotic cells. After cisplatin treatment, part of the A549/DDP cells showed apoptosis. Their nuclei and 
A

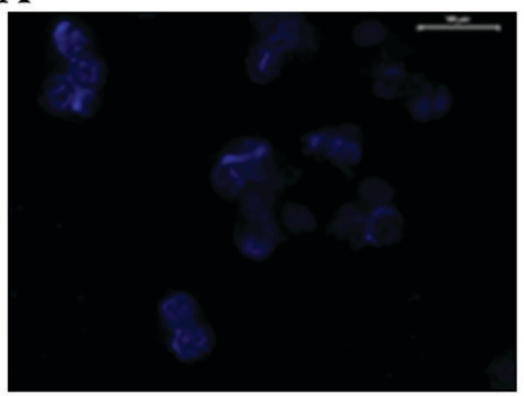

$\mathrm{C}$

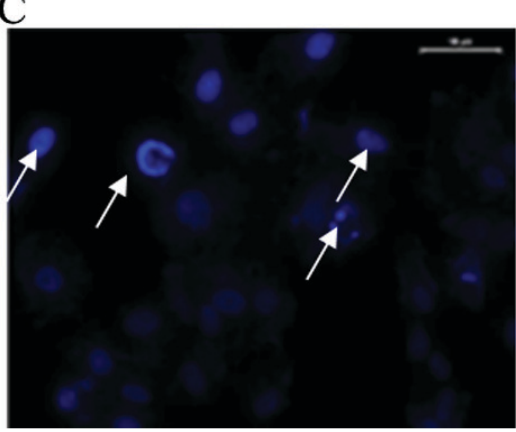

$\mathrm{B}$

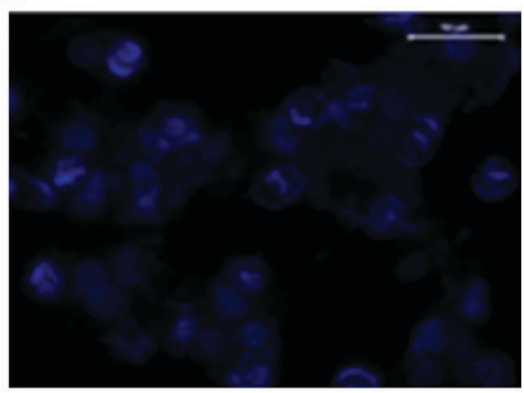

D

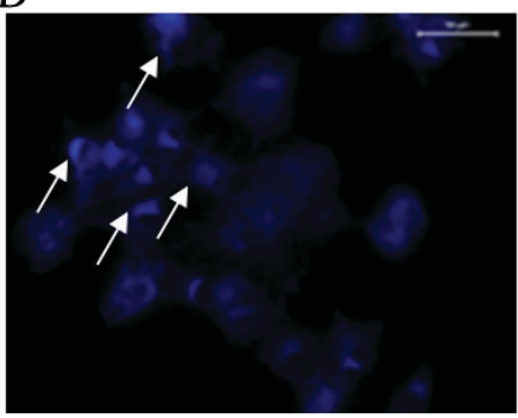

Figure 5. Cell apoptosis detected by Hoechst 33258. (A) A549/DDP cells with no treatment. (B) A549/DDP cells treated with $10 \mu \mathrm{mol} / 1$ 5-Aza-CdR (C) A549/DDP cells treated with $20 \mu \mathrm{mol} / 1$ cisplatin for $48 \mathrm{~h}$. (D) A549/DDP cells treated with $10 \mu \mathrm{mol} / 1$ 5-Aza-CdR and then $20 \mu \mathrm{mol} / 1 \mathrm{l}$ cisplatin for $48 \mathrm{~h}$.
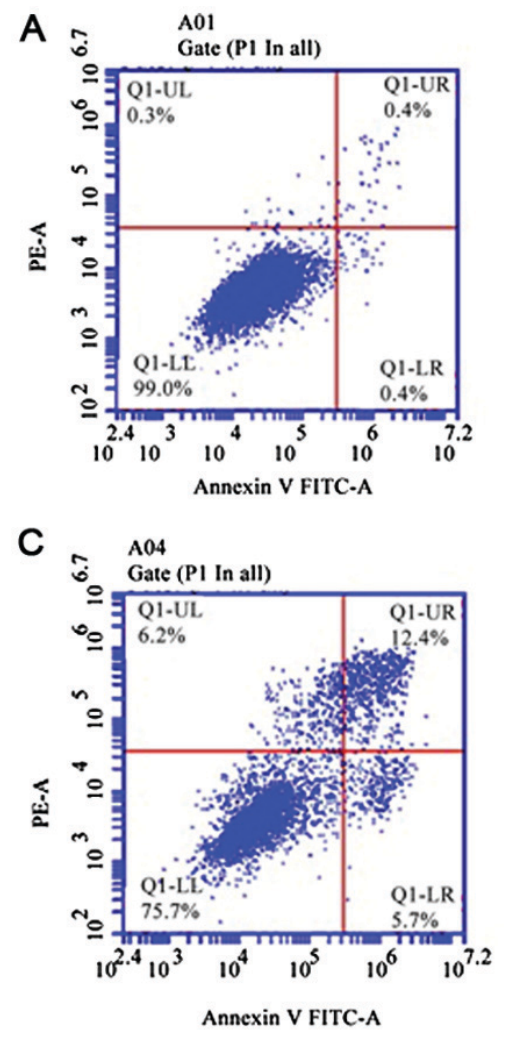

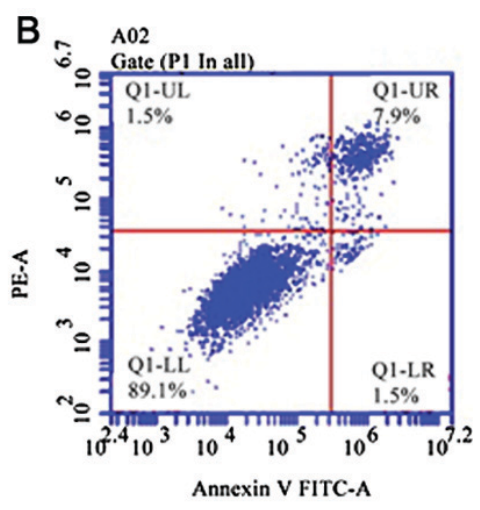

D



Figure 6. The effects of 5-Aza-CdR and different concentrations of cisplatin on A549/DDP cell apoptosis. A549/DDP cells treated with 0, 2.5, 10 or $40 \mu$ mol/1 cisplatin. (A) A549/DDP cells without treatment of cisplatin; (B) A549/DDP cells treated with $2.5 \mu \mathrm{mol} / 1$ cisplatin; (C) A549/DDP cells treated with $10 \mu \mathrm{mol} / 1$ cisplatin; (D) A549/DDP cells treated with $40 \mu \mathrm{mol} / \mathrm{l}$ cisplatin.

cytoplasm had dense fluorescent signals with different sizes and irregular or plum blossom-like shape. Apoptotic bodies could be observed. After 5-Aza-CdR intervention, apoptotic A549/DDP cells were significantly increased.
Cell apoptosis detected by flow cytometry. Flow cytometry results showed that A549/DDP cells had a low apoptotic ratio of $0.8 \pm 0.10 \%$ after $10 \mu \mathrm{mol} / 15$-Aza-CdR intervention, which indicates there is no cell apoptosis caused by $10 \mu \mathrm{mol} / \mathrm{l}$ 
5-Aza-CdR intervention after $48 \mathrm{~h}$. The apoptotic ratios of A549/DDP cells after 2.5, 10, or $40 \mu \mathrm{mol} / 1$ cisplatin and $10 \mu \mathrm{mol} / 1$ 5-Aza-CdR treatments were $9.40 \pm 0.86,18.10 \pm 1.42$, and $42.00 \pm 2.01 \%$, respectively (Fig. 6; Table II), which were significantly higher than that of the A549/DDP cells only treated with 5-Aza-CdR $(\mathrm{P}<0.05)$.

\section{Discussion}

General chemotherapy is one of the major means of treating non-small cell lung cancer (NSCLC) patients. Platinum drugs are a widely used class of chemotherapy drugs and have good treatment efficacy. Drug resistance in cancer cells is one the most common causes of failure in tumor chemotherapy. CDH13 is closely related to the occurrence and development of cancers. Previous studies found that $\mathrm{CDH} 13$ expression is downregulated in bladder, breast, cervical, and colon cancers, which is closely related to $\mathrm{CDH} 13$ methylation (30-34).

DNA methylation is a covalent modification to cytosine at the $\mathrm{CpG}$ sites of gene promoter region and exon 1. Abnormal methylation of $\mathrm{CpG}$ at promoter region can lead to silencing of gene transcription, e.g., the extremely low or no expression of many important genes, such as tumor suppressor genes, cells cycle regulatory genes, apoptosis-related genes $(35,36)$, which promotes the formation of tumor cells. However, DNA methylation is reversible, which provides a theoretical basis and new direction for reversal of tumor drug resistance. The drugs targeting this reversible process can be developed to enhance the drug sensitivity of tumor cells during chemotherapy. 5-Aza-CdR is a DNA methyltransferase inhibitor. Previous findings showed that non-toxic low doses of 5-Aza-CdR can reverse drug resistance in pancreatic cancer, neuroblastoma, ovarian cancer, and colon cancer (37). 5-Aza-CdR was first approved by the U.S. to be applied in chemotherapy of blood system tumors. It is also a first-line drug for chemotherapy of acute nonlymphocytic leukemia in patients older than 65 years. Currently, it has also been used for treating solid tumors, such as ovarian cancer (38-42).

In this study, we used the cisplatin-resistant NSCLC cell line A549/DDP and its parental cell line A549 (as the control group). We discovered that CDH13 mRNA was expressed in both cell lines, but its expression level in A549 cells was significantly higher than that of the cisplatin-resistant A549/ DDP cells, which indicates that the cisplatin resistance in lung cancer cells may be related to $\mathrm{CDH} 13$ silencing and protein expression deficiency. MSP results showed that 5-Aza-CdR could convert the partial methylation state of $\mathrm{CDH} 13$ to unmethylation state in A549/DDP cells and induce CDH13 expression in cisplatin-resistant A549/DDP cells. These results suggest that 5-Aza-CdR can reverse the cisplatin resistance in lung cancer cells.

We further studied the inhibition of A549/DDP cell proliferation and A549/DDP cell apoptosis after the reversal of CDH13 methylation by 5 -Aza-CdR treatment. We measured the reversal index of cisplatin resistance in A549/DDP cells after non-toxic low-dose 5-Aza-CdR treatment and analyzed the correlation between $\mathrm{CDH} 13$ methylation and cisplatin resistance in lung cancer cells. After $10 \mu \mathrm{mol} / 15$-Aza-CdR intervention, the $\mathrm{IC}_{50}$ value of $\mathrm{A} 549 / \mathrm{DDP}$ cells to cisplatin was significantly decreased, which was positively correlated with cell apoptosis and the inhibition of cell proliferation. With the increase in 5-Aza-CdR concentration, the cisplatin sensitivity in A549/DDP cells was significantly enhanced, which indicates that the cisplatin resistance in lung cancer cells may be closely related to methylation of CDH13 promoter region. Although the cisplatin resistance in A549/ DDP cells after 5-Aza-CdR intervention was reversed by 3.41-fold, it still had a significant difference with that of the parental A549 cells, which indicates the involvement of other genes in chemotherapy resistance. These drug-resistant genes may induce the drug resistance in lung cancer cells through different targets and mechanisms.

To compare the differentially expressed proteins between A549 cells and DDP (cisplatin)-resistant A549/DDP cells, A549 cells were exposed to DDP for developing the DDPresistant A549/DDP cells. Differentially expressed proteins in the A549 and A549/DDP cells were separated and identified by proteomics approach. A part of the differentially expressed proteins were validated by RT-PCR, western blot analysis and immunocytochemistry. The functions of these proteins were further explored. There were 8 differentially expressed proteins including POTE, FH (fumarate hydratase), PDE (phosphodiesterase), AKR1C1 (aldo-keto reductase family 1 member Cl), DDH2 (dihydrodiol dehydrogenase 2), S100A10, prefoldin subunit 2, and karyopherin $\beta 2$-Ran GppNHp nuclear transport complex between A549 and A549/DDP cells, and the difference in expression was $>5$-fold. These proteins were related with cellular metabolism, apoptosis, cell proliferation, detoxification and signal transduction (43-45).

CDH13, a member of the cadherin family, has been considered as a tumor suppressor, and the introduction of $\mathrm{CDH} 13$ in human tumor cells can reduce their invasive potential. In addition, $\mathrm{CDH} 13$ can induce the reversion of morphology from an invasive to a normal cell-like type. In a previous study, downregulated $\mathrm{CDH} 13$ protein expression was found in bladder TCC (26). However, the effects and mechanisms of downregulated CDH13 expression on bladder TCC invasion need to be further elucidated. The role of $\mathrm{CDH} 13$ in cancer invasion is not fully understood. In the current study, we assessed the role of $\mathrm{CDH} 13$ in bladder TCC invasiveness by silencing its expression using siRNA and assessed its effects on in vitro invasiveness, migration, and adhesion. We examined the CDH13 expression in CDH13 siRNA-transfected cells, blank control cells and negative control cells using qRT-PCR and western blotting. $\mathrm{CDH} 13$ expression was significantly decreased in CDH13 siRNA-treated cells compared with blank and negative controls at the mRNA and protein level (46).

DNA methylation is a DNA modification method. It regulates gene expression mainly through the methylation of cytosine in $\mathrm{CpG}$ sequence but does not change the DNA sequence. $\mathrm{CpG}$ island is a dispersed or highly aggregated sequence in DNA. Mutation or methylation of $\mathrm{CpG}$ island in the promoter region of tumor and suppressor gene $\mathrm{CDH} 13$ will affect $\mathrm{CDH} 13$ transcription, reduce $\mathrm{CDH} 13$ expression, and thus promote tumor cell proliferation and induce lung cancer development $(21,47,48)$. When CDH13 promoter region was methylated, the ability of $\mathrm{CDH} 13$ to recognize DNA damage was weakened, and DNA continued to be replicated, which resulted in the formation of drug resistance. This theory was consistent with the finding in our study that CDH13 
methylation was associated with cisplatin resistance in lung cancer cells. However, whether the underlying mechanisms were the same still needs further study.

Early discovery is critical for cancer treatment. During the early stage of tumorigenesis, abnormal DNA methylation occurs and can be detected, which provides a basis for early diagnosis of cancer. Since DNA methylation is a reversible gene-modification process, demethylation treatment before tumor generation can restore gene expression and achieve tumor prevention and treatment. In this study, our results showed that methylation of $\mathrm{CDH} 13$ promoter region in drug-resistant A549/DDP cells is an important cause of the reduction of $\mathrm{CDH} 13$ transcription. Inhibition of $\mathrm{CDH} 13$ methylation can restore CDH13 expression, reverse tumor cell biologic activity and change drug resistance phenotype in NSCLC cells. Therefore, this study provided a new target for NSCLC chemotherapy in the future.

\section{Acknowledgements}

Not applicable.

\section{Funding}

No funding was received.

\section{Availability of data and materials}

The datasets used and/or analyzed during the present study are available from the corresponding author on reasonable request.

\section{Authors' contributions}

YW, LZ and JW conceived and designed the study. YW, LZ, JY, BL and JW were responsible for the collection and analysis of the experimental data. YW and LZ interpreted the data and drafted the manuscript. JY and JW revised the manuscript critically for important intellectual content. All authors read and approved the final study.

\section{Ethics approval and consent to participate}

The study was approved by the Ethics Committee of Guangdong Second Provincial General Hospital (Guangzhou, China)

\section{Patient consent for publication}

Not applicable.

\section{Competing interests}

The authors declare that they have no competing interests.

\section{References}

1. Drilon A, Sugita H, Sima CS, Zauderer M, Rudin CM, Kris MG, Rusch VW and Azzoli CG: A prospective study of tumor suppressor gene methylation as a prognostic biomarker in surgically resected stage I to IIIA non-small-cell lung cancers. J Thorac Oncol 9: 1272-1277, 2014.
2. Morisaki H, Yamanaka I, Iwai N, Miyamoto Y, Kokubo Y, Okamura T, Okayama A and Morisaki T: CDH13 gene coding T-cadherin influences variations in plasma adiponectin levels in the Japanese population. Hum Mutat 33: 402-410, 2012.

3. Chung CM, Lin TH, Chen JW, Leu HB, Yang HC, Ho HY, Ting CT, Sheu SH, Tsai WC, Chen JH, et al: A genome-wide association study reveals a quantitative trait locus of adiponectin on CDH13 that predicts cardiometabolic outcomes. Diabetes 60: 2417-2423, 2011.

4. Hulpiau P and van Roy F: Molecular evolution of the cadherin superfamily. Int J Biochem Cell Biol 41: 349-369, 2009.

5. Dames SA, Bang E, Haüssinger D, Ahrens T, Engel J and Grzesiek S: Insights into the low adhesive capacity of human T-cadherin from the NMR structure of Its N-terminal extracellular domain. J Biol Chem 283: 23485-23495, 2008.

6. Ciatto C, Bahna F, Zampieri N, VanSteenhouse HC, Katsamba PS, Ahlsen G, Harrison OJ, Brasch J, Jin X, Posy S, et al: T-cadherin structures reveal a novel adhesive binding mechanism. Nat Struct Mol Biol 17: 339-347, 2010.

7. Liu T, Qian WJ, Gritsenko MA, Camp DG II, Monroe ME, Moore RJ and Smith RD: Human plasma N-glycoproteome analysis by immunoaffinity subtraction, hydrazide chemistry, and mass spectrometry. J Proteome Res 4: 2070-2080, 2005.

8. Chen R, Jiang X, Sun D, Han G, Wang F, Ye M, Wang L and Zou H: Glycoproteomics analysis of human liver tissue by combination of multiple enzyme digestion and hydrazide chemistry. J Proteome Res 8: 651-661, 2009.

9. Philippova M, Joshi MB, Kyriakakis E, Pfaff D, Erne P and Resink TJ: A guide and guard: The many faces of T-cadherin. Cell Signal 21: 1035-1044, 2009.

10. Resink TJ, Philippova M, Joshi MB, Kyriakakis E and Erne P: Cadherins and cardiovascular disease. Swiss Med Wkly 139: 122-134, 2009.

11. Andreeva AV, Kutuzov MA, Tkachuk VA and VoynoYasenetskaya TA: T-cadherin is located in the nucleus and centrosomes in endothelial cells. Am J Physiol Cell Physiol 297: C1168-C1177, 2009.

12. Emond MR and Jontes JD: Inhibition of protocadherin-alpha function results in neuronal death in the developing zebrafish. Dev Biol 321: 175-187, 2008.

13. Haas IG, Frank M, Véron N and Kemler R: Presenilin-dependent processing and nuclear function of gamma-protocadherins. J Biol Chem 280: 9313-9319, 2005.

14. Magg T, Schreiner D, Solis GP, Bade EG and Hofer HW: Processing of the human protocadherin Fatl and translocation of its cytoplasmic domain to the nucleus. Exp Cell Res 307: 100-108, 2005.

15. Hou R, Liu L, Anees S, Hiroyasu S and Sibinga NE: The Fat1 cadherin integrates vascular smooth muscle cell growth and migration signals. J Cell Biol 173: 417-429, 2006.

16. Ferber EC, Kajita M, Wadlow A, Tobiansky L, Niessen C, Ariga H, Daniel J and Fujita Y: A role for the cleaved cytoplasmic domain of E-cadherin in the nucleus. J Biol Chem 283: 12691-12700, 2008.

17. Shoval I, Ludwig A and Kalcheim C: Antagonistic roles of full-length N-cadherin and its soluble BMP cleavage product in neural crest delamination. Development 134: 491-501, 2007.

18. Mukherjee S, Tessema M and Wandinger-Ness A: Vesicular trafficking of tyrosine kinase receptors and associated proteins in the regulation of signaling and vascular function. Circ Res 98: 743-756, 2006.

19. Takeuchi T and Ohtsuki Y: Recent progress in T-cadherin (CDH13, H-cadherin) research. Histol Histopathol 16: 1287-1293, 2001.

20. Sato M, Mori Y, Sakurada A, Fujimura S and Horii A: The $\mathrm{H}$-cadherin (CDH13) gene is inactivated in human lung cancer. Hum Genet 103: 96-101, 1998.

21. Zhong YH, Peng H, Cheng HZ and Wang P: Quantitative assessment of the diagnostic role of $\mathrm{CDH} 13$ promoter methylation in lung cancer. Asian Pac J Cancer Prev 16: 1139-1143, 2015.

22. Kim H, Kwon YM, Kim JS, Lee H, Park JH, Shim YM, Han J, Park $\mathbf{J}$ and Kim DH: Tumor-specific methylation in bronchial lavage for the early detection of non-small-cell lung cancer. J Clin Oncol 22: 2363-2370, 2004.

23. Hanabata T, Tsukuda K, Toyooka S, Yano M, Aoe M, Nagahiro I, Sano Y, Date H and Shimizu N: DNA methylation of multiple genes and clinicopathological relationship of non-small cell lung cancers. Oncol Rep 12: 177-180, 2004. 
24. Toyooka KO, Toyooka S, Virmani AK, Sathyanarayana UG, Euhus DM, Gilcrease M, Minna JD and Gazdar AF: Loss of expression and aberrant methylation of the CDH13 (H-cadherin) gene in breast and lung carcinomas. Cancer Res 61: 4556-4560, 2001.

25. Morisaki H, Yamanaka I, Iwai N, Miyamoto Y, Kokubo Y, Okamura T, Okayama A and Morisaki T: CDH13 gene coding T-cadherin influences variations in plasma adiponectin levels in the Japanese population. Hum Mutat 33: 402-410, 2012.

26. Chen F, Huang T, Ren Y, Wei J, Lou Z, Wang X, Fan X, Chen Y, Weng $\mathrm{G}$ and Yao X: Clinical significance of $\mathrm{CDH} 13$ promoter methylation as a biomarker for bladder cancer: A meta-analysis. BMC Urol 16: 52, 2016.

27. Guo Q, Wang HB, Li YH, Li HF, Li TT, Zhang WX, Xiang SS and Sun ZQ: Correlations of promoter methylation in WIF-1, RASSF1A, and CDH13 genes with the risk and prognosis of esophageal cancer. Med Sci Monit 22: 2816-2824, 2016.

28. Grady WM, Willis J, Guilford PJ, Dunbier AK, Toro TT, Lynch H, Wiesner G, Ferguson K, Eng C, Park JG, et al: Methylation of the $\mathrm{CDH} 1$ promoter as the second genetic hit in hereditary diffuse gastric cancer. Nat Genet 26: 16-17, 2000.

29. Andreeva AV and Kutuzov MA: Cadherin 13 in cancer. Genes Chromosomes Cancer 49: 775-790, 2010.

30. Lin YL, Xie PG and Ma JG: Aberrant methylation of CDH13 is a potential biomarker for predicting the recurrence and progression of non muscle invasive bladder cancer. Med Sci Monit 20: 1572-1577, 2014.

31. Widschwendter A, Ivarsson L, Blassnig A, Müller HM, Fiegl H, Wiedemair A, Müller-Holzner E, Goebel G, Marth C and Widschwendter M: CDH1 and CDH13 methylation in serum is an independent prognostic marker in cervical cancer patients. Int J Cancer 109: 163-166, 2004.

32. Yang J, Niu H, Huang Y and Yang K: A systematic analysis of the relationship of $\mathrm{CDH} 13$ promoter methylation and breast cancer risk and prognosis. PLoS One 11: e0149185, 2016.

33. Hibi K, Kodera Y, Ito K, Akiyama S and Nakao A: Methylation pattern of CDH13 gene in digestive tract cancers. Br J Cancer 91: $1139-1142,2004$

34. Ren JZ and Huo JR: Correlation between T-cadherin gene expression and aberrant methylation of T-cadherin promoter in human colon carcinoma cells. Med Oncol 29: 915-918, 2012.

35. Toyooka S, Toyooka KO, Maruyama R, Virmani AK, Girard L, Miyajima K, Harada K, Ariyoshi Y, Takahashi T, Sugio K, et al: DNA methylation profiles of lung tumors. Mol Cancer Ther 1: 61-67, 2001.

36. Birchmeier W and Behrens J: Cadherin expression in carcinomas: Role in the formation of cell junctions and the prevention of invasiveness. Biochim Biophys Acta 1198: 11-26, 1994.

37. Gayet O, Loncle C, Duconseil P, Gilabert M, Lopez MB, Moutardier V, Turrini O, Calvo E, Ewald J, Giovannini M, et al: A subgroup of pancreatic adenocarcinoma is sensitive to the 5-aza-dC DNA methyltransferase inhibitor. Oncotarget 6 : 746-754, 2015
38. Yang AS, Doshi KD, Choi SW, Mason JB, Mannari RK, Gharybian V, Luna R, Rashid A, Shen L, Estecio MR, et al: DNA methylation changes after 5-aza-2'-deoxycytidine therapy in patients with leukemia. Cancer Res 66: 5495-5503, 2006.

39. Nguyen TT, Mohrbacher AF, Tsai YC, Groffen J, Heisterkamp N, Nichols PW, Yu MC, Lübbert M and Jones PA: Quantitative measure of c-abl and p15 methylation in chronic myelogenous leukemia: Biological implications. Blood 95: 2990-2992, 2000.

40. Blum W, Schwind S, Tarighat SS, Geyer S, Eisfeld AK, Whitman S, Walker A, Klisovic R, Byrd JC, Santhanam R, et al: Clinical and pharmacodynamic activity of bortezomib and decitabine in acute myeloid leukemia. Blood 119: 6025-6031, 2012.

41. Cowan LA, Talwar S and Yang AS: Will DNA methylation inhibitors work in solid tumors? A review of the clinical experience with azacitidine and decitabine in solid tumors. Epigenomics 2: 71-86, 2010.

42. Nicholson LJ, Smith PR, Hiller L, Szlosarek PW, Kimberley C, Sehouli J, Koensgen D, Mustea A, Schmid P and Crook T: Epigenetic silencing of argininosuccinate synthetase confers resistance to platinum-induced cell death but collateral sensitivity to arginine auxotrophy in ovarian cancer. Int J Cancer 125: 1454-1463, 2009

43. Kuang P, Li XF, Li B, Wang YS, Li JY and Zhou CC: Comparative proteomic analysis of human lung adenocarcinoma A549 and A549/DDP cells. Tumor 32: 170-176, 2012.

44. Qin X, Yu S, Xu X, Shen B and Feng J: Comparative analysis of microRNA expression profiles between A549, A549/DDP and their respective exosomes. Oncotarget 8: 42125-42135, 2017.

45. Ye LY, Hu S, Xu HE, Xu RR, Kong H, Zeng XN, Xie WP and Wang $\mathrm{H}$ : The effect of tetrandrine combined with cisplatin on proliferation and apoptosis of A549/DDP cells and A549 cells. Cancer Cell Int 17: 40, 2017.

46. Lin YL, He ZK, Li ZG and Guan TY: Downregulation of CDH13 expression promotes invasiveness of bladder transitional cell carcinoma. Urol Int 90: 225-232, 2013.

47. Kontic M, Stojsic J, Jovanovic D, Bunjevacki V, Ognjanovic S, Kuriger J, Puumala S and Nelson HH: Aberrant promoter methylation of CDH13 and MGMT genes is associated with clinicopathologic characteristics of primary non-small-cell lung carcinoma. Clin Lung Cancer 13: 297-303, 2012.

48. Zhai X and Li SJ: Methylation of RASSF1A and CDH13 genes in individualized chemotherapy for patients with non-small cell lung cancer. Asian Pac J Cancer Prev 15: 4925-4928, 2014. International (CC BY-NC-ND 4.0) License. 